\title{
The effect of thrombolysis on short-term improvement depends on initial stroke severity
}

\author{
George Ntaios • Mohamed Faouzi · Patrik Michel
}

Received: 26 April 2011/Revised: 4 August 2011/Accepted: 6 August 2011/Published online: 30 August 2011

(C) Springer-Verlag 2011

\begin{abstract}
A large number of parameters have been identified as predictors of early outcome in patients with acute ischemic stroke. In the present work we analyzed a wide range of demographic, metabolic, physiological, clinical, laboratory and neuroimaging parameters in a large population of consecutive patients with acute ischemic stroke with the aim of identifying independent predictors of the early clinical course. We used prospectively collected data from the Acute Stroke Registry and Analysis of Lausanne. All consecutive patients with ischemic stroke admitted to our stroke unit and/or intensive care unit between 1 January 2003 and 12 December 2008 within $24 \mathrm{~h}$ after last-well time were analyzed. Univariate and multivariate analyses were performed to identify significant associations with the National Institute of Health Stroke Scale (NIHSS) score at admission and $24 \mathrm{~h}$ later. We also sought any interactions between the identified predictors. Of the 1,730 consecutive patients with acute ischemic stroke who were included in the analysis, $260(15.0 \%)$ were thrombolyzed (mostly intravenously) within the recommended time window. In multivariate analysis, the NIHSS score at $24 \mathrm{~h}$ after admission was associated with the NIHSS score at admission $(\beta=1, p<0.001)$, initial glucose level $(\beta=0.05, \quad p<0.002)$ and thrombolytic intervention
\end{abstract}

G. Ntaios $(\varangle) \cdot$ P. Michel

Neurology Service, Center Hospitalier Universitaire Vaudois, University of Lausanne, Rue du Bugnon 46, 1011 Lausanne, Switzerland

e-mail: ntaiosgeorge@yahoo.gr

M. Faouzi

Institute of Social and Preventive Medicine, Center Hospitalier Universitaire Vaudois, University of Lausanne, Lausanne, Switzerland $(\beta=-2.91, p<0.001)$. There was a significant interaction between thrombolysis and the NIHSS score at admission $(p<0.001)$, indicating that the short-term effect of thrombolysis decreases with increasing initial stroke severity. Thrombolytic treatment, lower initial glucose level and lower initial stroke severity predict a favorable early clinical course. The short-term effect of thrombolysis appears mainly in minor and moderate strokes, and decreases with increasing initial stroke severity.

Keywords Stroke severity - Severe strokes . Thrombolysis · Glucose

\section{Introduction}

Several prognostic models have been developed and validated to predict long-term outcome in patients with acute stroke [1-4]. These indices include several variables including age, the National Institute of Health Stroke Scale (NIHSS) score, gender, prior stroke, diabetes mellitus and fever. Such models provide prognostic information that can be provided to the patient and family, and also help clinicians in making decisions regarding treatment and rehabilitation. However, fewer data are available regarding the predictors of the early course following acute stroke [5], and studies have been limited by a small sample size or have involved the analysis of a limited number of variables.

In the present study we analyzed a wide range of demographic, metabolic, physiological, clinical, laboratory and neuroimaging parameters in a large population of patients with acute ischemic stroke with the aim of identifying independent predictors of the early clinical course. 


\section{Methods}

We used prospectively collected data from the Acute Stroke Registry and Analysis of Lausanne (ASTRAL) [6]. All consecutive patients who were admitted to the stroke unit and/or intensive care unit of our hospital between 1 January 2003 and 12 December 2008 within $24 \mathrm{~h}$ of the last-well time with a main diagnosis of acute ischemic stroke were prospectively included. Recurrent strokes were registered as new events if they led to a new admission. Exclusion criteria included transient ischemic attack (TIA), intracerebral hemorrhage, subarachnoidal hemorrhage, cerebral sinus venous thrombosis and late admission ( $>24 \mathrm{~h}$ after stroke onset). Stroke severity at $24 \mathrm{~h}$ as measured using the NIHSS score after admission was the main outcome. Acute recanalization treatments were given according to the recommendations of the European Stroke Organization [7]: before the publication of ECASS-III [8], intravenous thrombolysis given within $3 \mathrm{~h}$ and within $4.5 \mathrm{~h}$ thereafter, and endovascular treatments within $6 \mathrm{~h}$; these patients were considered as treated "within the recommended time window" in the current analysis. Symptomatic intracranial hemorrhage (sICH) within the first $24 \mathrm{~h}$ was defined according to the ECASS-II criteria [9]. Stroke etiology was classified according to the TOAST classification [10].

Demographic data (age, gender, ethnicity, insurance), metabolic parameters (glucose, creatinine, cholesterol levels), full blood count, physiological parameters (temperature, heart rate, blood pressure) and the NIHSS score at admission and $24 \mathrm{~h}$ after admission were prospectively recorded for each patient. When possible, NIHSS scores were determined by a NIHSS-certified stroke unit physician who was not blinded to the treatment. When the NIHSS scores were determined by a noncertified physician (particularly during night and weekend duties), they were discussed between the assessing and a NIHSS-certified physician the next working day. In intubated patients, NIHSS score determinations were in general performed before intubation, and an effort was made to assess the NIHSS score during a window without sedation. If more than one blood pressure measurement was available at admission or at 24-48 h, the first recording was registered. Moreover, a systematic search was performed for every patient to identify vascular risk factors including arterial hypertension, atrial fibrillation, diabetes mellitus, valvulopathy, coronary artery disease and smoking. Also recorded were prehospital Rankin score (mRS), previous strokes, TIAs or retinal ischemia, as well as prior medication. Finally, silent lesions, leukoaraiosis and early ischemic changes on brain CT scans were recorded as well as arterial stenosis/occlusion, since all patients underwent brain parenchymal (mostly CT) and arterial (mostly CT angiography) imaging. Extra- and/or intracranial stenosis of $>50 \%$ or occlusion of the arteries supplying the ischemic territory was considered significant.

This study was approved by the ethics committee of our institution and was therefore performed in accordance with the ethical standards laid down in the 1964 Declaration of Helsinki.

\section{Statistical analysis}

In this retrospective analysis, heart rate, ejection fraction and temperature were analyzed as categorical variables, with the cut-off values at $90 \mathrm{~min}^{-1}, 30 \%$ and $38^{\circ} \mathrm{C}$, respectively. Blood pressure was analyzed as a continuous variable. Laboratory values were analyzed as continuous variables and are reported as median (interquartile range, IQR). NIHSS scores at admission and $24 \mathrm{~h}$ later were analyzed as continuous variables.

All parameters presented in Table 1 were included in a univariate analysis to identify significant associations with NIHSS score at $24 \mathrm{~h}$ after admission. The parameters found to be of statistical significance $(p<0.05)$ were entered in a multivariate robust regression analysis model to search for independent associations. The level of significance was set at $95 \%(p=0.05)$.

\section{Results}

Between 1 January 2003 and 12 December 2008, 3,165 patients with an acute ischemic stroke were admitted to the stroke unit or intensive care unit. Of these, 1,435 (45.3\%) were excluded for the following reasons: intracerebral hemorrhage (166 patients, 5.2\%), TIA (577, 18.2\%), late admission $(623,19.7 \%)$, ocular ischemia $(57,1.8 \%)$ and lack of NIHSS score at $24 \mathrm{~h}(12,0.4 \%)$. Finally, 1,730 patients with acute ischemic stroke were included in our analysis. Interestingly, $41 \%$ of patients had a prehospital $\mathrm{mRS}$ of $\geq 1$, probably due to the fact that we did not analyze only first-ever strokes, but also recurrences.

Table 1 summarizes the main demographic, clinical, laboratory and imaging data of the patients. The median NIHSS score was 6 (IQR 3-14) at admission and 4 (IQR 2-11) $24 \mathrm{~h}$ later. There was no interaction between NIHSS score at admission and the infarct side. Thrombolysis was performed within the recommended time limits in 260 patients $(15.0 \%$, of which $0.8 \%$ were acute endovascular treatments), of whom $10(3.8 \%)$ had a NIHSS score of 4 , none had a score of 3 and $1(0.4 \%)$ had a score of 2 . Only one of the nonthrombolyzed patient and $5(1.9 \%)$ of the thrombolyzed patients suffered a sICH. The admission NIHSS score of the patients with sICH was $\geq 21$ in two (33\%), 16-21 in two (33\%) and $10-15$ in two (33\%); no 
Table 1 Patient characteristics $(n=1,730)$

\begin{tabular}{|c|c|}
\hline Characteristic & Value \\
\hline \multicolumn{2}{|l|}{ Demographics } \\
\hline Age (years) & $72(60-81)$ \\
\hline Female gender & $766(44.3 \%)$ \\
\hline \multicolumn{2}{|l|}{ Last-well time to admission time (min) } \\
\hline Known-onset stroke & $137(87-198)$ \\
\hline Unknown-onset stroke & $753(496-980)$ \\
\hline \multicolumn{2}{|c|}{ Laboratory measurements (within $24 \mathrm{~h}$ of stroke onset) } \\
\hline Hemoglobin $(\mathrm{g} / \mathrm{l})$ & $140(129-151)$ \\
\hline White blood cell count $\left(\times 10^{3} / 1\right)$ & $8.1(6.5-10.7)$ \\
\hline Platelet count $\left(\times 10^{3} / 1\right)$ & $225.0(186-273)$ \\
\hline Glucose $(\mathrm{mmol} / \mathrm{l})$ & $6.5(5.7-7.9)$ \\
\hline Creatinine $(\mathrm{mmol} / \mathrm{l})$ & $90(75-107)$ \\
\hline Total cholesterol (mmol/l) & $5.4(4.6-6.5)$ \\
\hline \multicolumn{2}{|c|}{ Vital signs/Clinical examination (at admission) } \\
\hline Temperature $\left({ }^{\circ} \mathrm{C}\right)$ & $36.4(36.0-36.8)$ \\
\hline Heart rate $\left(\min ^{-1}\right)$ & $77.5(67.7-90.0)$ \\
\hline Systolic blood pressure $(\mathrm{mmHg})$ & $158(140-178)$ \\
\hline Diastolic blood pressure (mmHg) & $89(80-100)$ \\
\hline NIHSS score $\leq 4$ & $705(40.6 \%)$ \\
\hline NIHSS score $>22$ & $115(6.6 \%)$ \\
\hline \multicolumn{2}{|l|}{ Site of infarction } \\
\hline Right & $717(41.5 \%)$ \\
\hline Left & $836(48.3 \%)$ \\
\hline Bilateral & $163(9.4 \%)$ \\
\hline Undetermined & $14(0.8 \%)$ \\
\hline \multicolumn{2}{|l|}{ Arterial territory affected } \\
\hline Anterior circulation & $1,074(62.1 \%)$ \\
\hline Vertebrobasilar circulation & $502(29 \%)$ \\
\hline Both territories & $21(1.2 \%)$ \\
\hline Undetermined & $133(7.7 \%)$ \\
\hline \multicolumn{2}{|l|}{ Medical history/Previous treatment } \\
\hline Hypertension & $1,151(66.5 \%)$ \\
\hline Atrial fibrillation & $438(25.3 \%)$ \\
\hline Diabetes mellitus & $233(13.5 \%)$ \\
\hline Newly diagnosed diabetes mellitus & $30(1.7 \%)$ \\
\hline Prosthetic valve/mechanical/biological & $58 / 45 / 13(3.4 \%)$ \\
\hline Coronary artery disease & $262(15.1 \%)$ \\
\hline Smoking & $411(23.8 \%)$ \\
\hline Previous stroke(s)/TIA(s) & $462(26.7 \%)$ \\
\hline Antiplatelet treatment & $655(37.8 \%)$ \\
\hline Antihypertensive agents & $932(53.7 \%)$ \\
\hline Oral hypoglycemic agents & $137(7.9 \%)$ \\
\hline Insulin & $60(3.5 \%)$ \\
\hline Anticoagulant & $171(9.9 \%)$ \\
\hline Lipid-lowering drugs & $393(22.7 \%)$ \\
\hline Prestroke Rankin score 0 & $1,020(59.0 \%)$ \\
\hline \multicolumn{2}{|l|}{$\begin{array}{l}\text { Thrombolysis within recommended } \\
\text { time limits }\end{array}$} \\
\hline Intravenous & $246(14.2 \%)$ \\
\hline
\end{tabular}

Table 1 continued

\begin{tabular}{lc}
\hline Characteristic & \multicolumn{2}{l}{ Value } \\
\hline Intraarterial & $14(0.8 \%)$ \\
Symptomatic hemorrhagic transformation & $5(1.9 \%)$ \\
Imaging study findings & \\
Silent lesions on brain CT scan & $380(22.0 \%)$ \\
Acute ischemic lesions on brain CT scan at & $531(30.7 \%)$ \\
admission & \\
Leukoaraiosis & $360(20.8 \%)$ \\
Significant pathology on arterial imaging & $668(38.6 \%)$ \\
Stroke subtypes & \\
Atherosclerotic ( $>50 \%$ stenosis) & $218(12.6 \%)$ \\
Possibly atherosclerotic (<50\% stenosis) & $252(14.6 \%)$ \\
Cardioembolic & $501(29.0 \%)$ \\
Dissection & $83(4.8 \%)$ \\
Lacunar/microangiopathy & $260(15.0 \%)$ \\
Other/rare & $68(3.9 \%)$ \\
Multiple/coexisting & $84(4.9 \%)$ \\
Unknown & $190(11.0 \%)$ \\
Patent foramen ovale & $67(3.9 \%)$ \\
\hline
\end{tabular}

Categorical variables are presented as $n(\%)$. Continuous variables are presented as median (interquartile range).

patient with an admission NIHSS score $\leq 4$ suffered a $\mathrm{SICH}$.

In the univariate analysis, 16 variables showed a significant association with the NIHSS score at $24 \mathrm{~h}$ after admission (Table 2). However, only initial stroke severity $(\beta=1, p<0.001)$, glucose level $(\beta=0.05, p=0.002)$ and thrombolytic intervention $(\beta=-2.91, p<0.001)$ remained significant in the multivariate analysis. A significant interaction $(p<0.001)$ was identified between the admission NIHSS score and intervention (Fig. 1). This interaction was no longer statistically significant for NIHSS scores of $>21$. This interaction remained significant after excluding patients (a) with a low NIHSS score $(\leq 4)$, (b) treated with intraarterial thrombolysis, and (c) with a sICH. We also sought to determine whether this interaction remained when the end-point was a favorable functional outcome at 3 and 12 months (as represented by a mRS $\leq 2$ ); however, this was not the case, since thrombolysis was no longer a significant predictor of outcome.

\section{Discussion}

Initial stroke severity, thrombolytic treatment and glucose levels were correlated with the early neurological course as measured by the NIHSS score at $24 \mathrm{~h}$ after admission. In particular, thrombolytic intervention improved the early clinical course in patients with minor and moderate strokes, 
Table 2 Uni- and multivariate analysis of predictors of NIHSS score at $24 \mathrm{~h}$ after admission
All parameters were assessed at admission. Only significant values are presented.

\begin{tabular}{|c|c|c|c|c|}
\hline \multirow[t]{2}{*}{ Variable } & \multicolumn{2}{|c|}{ Univariate analysis } & \multicolumn{2}{|c|}{ Multivariate analysis } \\
\hline & $\beta$ & $p$ value & $\beta$ & $p$ value \\
\hline NIHSS score at admission & 1 & $<0.001$ & 1 & $<0.001$ \\
\hline NIHSS score at $4-6 \mathrm{~h}$ & 1 & $<0.001$ & & \\
\hline Temperature & 2.67 & 0.001 & & \\
\hline Heart rate & 1.47 & $<0.001$ & & \\
\hline Glucose & 0.27 & $<0.001$ & 0.05 & 0.002 \\
\hline C-reactive protein & 0.11 & $<0.001$ & & \\
\hline White cell count & 0.54 & $<0.001$ & & \\
\hline Hemoglobin & -0.29 & 0.001 & & \\
\hline Red cell distribution width & 0.24 & 0.01 & & \\
\hline Age & 0.03 & $<0.001$ & & \\
\hline Gender (female) & -0.92 & 0.001 & & \\
\hline Prehospital Rankin score & 1.03 & $<0.001$ & & \\
\hline Atrial fibrillation & 1.74 & $<0.001$ & & \\
\hline Intervention & 4.21 & $<0.001$ & -2.91 & $<0.001$ \\
\hline Acute ischemic lesion on CT/MRI at admission & 5.77 & $<0.001$ & & \\
\hline Significant arterial pathology & 5.27 & $<0.001$ & & \\
\hline
\end{tabular}

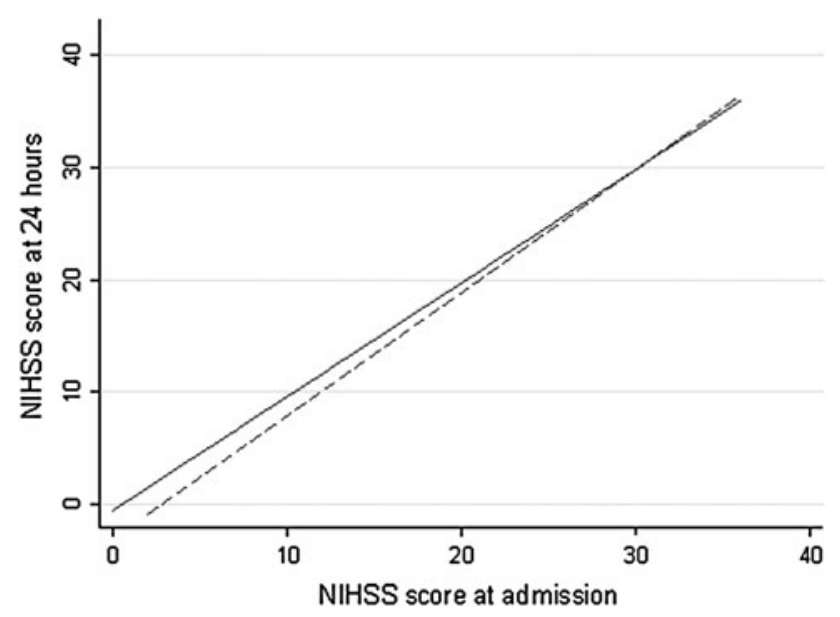

Fig. 1 Relationship between admission NIHSS score and 24-h NIHSS score at a fixed level of acute glucose (dashed line intervention patients, continuous line nonthrombolyzed patients)

but its effect decreased with increasing initial stroke severity.

Currently, the upper NIHSS score for intravenous thrombolysis as set by the European Medicines Agency is 25 [11], whereas the US Food and Drug Administration states that the risks of treating acute ischemic stroke with alteplase may be increased in patients with a severe neurological deficit (NIHSS score $>22$ ) and should be weighed against the anticipated benefits [12]. The rationale for this recommendation is based on the fact that the safety and efficacy of thrombolysis in patients with severe stroke have not been tested in randomized controlled trials, since such patients are usually excluded from thrombolysis trials. Our findings from a stroke center which currently does not have an upper exclusion limit for severe strokes, show that the effect of thrombolysis decreases with increasing initial stroke severity. Recently, an analysis of the Virtual International Stroke Trials Archive (VISTA) has shown that the significant association of outcome with thrombolysis is lost if the baseline NIHSS score is $\geq 24$, which the authors attributed to small sample size and wide confidence intervals [13]. Also, a high baseline NIHSS score was an independent predictor of poor outcome in the Safe Implementation of Thrombolysis in Stroke-Monitoring Study (SITS-MOST) [14]. A subgroup analysis of the ECASS-III trial [15] and a pooled analysis of the ATLANTIS, ECASS and NINDS rTPA trials [16] did not provide strong evidence to support exclusion of patients from treatment based on their initial NIHSS score for any onset-to-treatment interval; however, patients with a very severe stroke were under-represented in these trials, therefore limiting the amount of data from patients with a high NIHSS score. Further studies are warranted to provide more reliable conclusions.

In a recent analysis of the same dataset, we showed that hyper- and hypoglycemia after stroke is deleterious in acute ischemic stroke. We found a J-shaped association between glucose and the 24-h and 12-month outcome [17]. The negative effect of hyperglycemia on short-term outcome may be due to accelerated penumbra loss from high glucose values [18, 19] and underlines the need to pay particular attention to proper glucose management in acute stroke. We failed to identify an association between initial blood pressure and outcome. Previous studies have yielded controversial results about the effect of blood pressure on stroke severity and outcome [20]. Accordingly, it is still 
unclear whether its active treatment influences stroke outcome, which is reflected by the level of recommendation in the European Stroke Organisation and American Heart Association/American Stroke Association guidelines on stroke management [7, 21]. Several other well-known predictors of early and late outcome, such as age, chronic and early ischemic changes on neuroimaging, prehospital disability, admission temperature, white cell count and stroke mechanism were not confirmed in our sample; the likely explanation is that most of these parameters were predictors of the baseline NIHSS score in our population (data not shown), which in turn predicted the NIHSS score at $24 \mathrm{~h}$ after admission better than these factors themselves. Also, we failed to identify an association between thrombolysis and outcome. We suggest that this may have been due to the moderately small sample size of the study.

The strengths of our study include the large sample size and the wide variety of analyzed parameters, including demographic, clinical, metabolic, physiological, laboratory and neuroimaging variables. In contrast, this study had certain limitations. Firstly, we did not measure initial and final infarct volume, which could have provided a deeper insight into the pathophysiological basis of the reported associations. Secondly, arterial status, recanalization and stroke localization were not included in the current analysis. Thirdly, few of our patients received acute endovascular treatments, limiting the possibility of detecting an effect of different recanalization treatments. Finally, this was an observational retrospective study and patients were not randomized to treatment.

In conclusion, initial stroke severity, thrombolytic treatment, and initial glucose values predict the early clinical course over $24 \mathrm{~h}$. Thrombolytic intervention improved early clinical progression in patients with minor and moderate stroke, but its effect decreased with increasing initial stroke severity. According to these results, treatment modalities other than standard intravenous thrombolysis need to be explored in patients with severe stroke.

Acknowledgments This study was supported by grants from the Swiss Cardiology Foundation and Cardiomet-CHUV.

Conflict of interest P.M. receives funding from Paion and Lundbeck (research support and consulting fees also used for research and education) and Boehringer-Ingelheim (advisory board, fees used for research).

\section{References}

1. Counsell C, Dennis M, McDowall M (2004) Predicting functional outcome in acute stroke: comparison of a simple six variable model with other predictive systems and informal clinical prediction. J Neurol Neurosurg Psychiatry 75:401-405

2. Konig IR, Ziegler A, Bluhmki E, Hacke W, Bath PM, Sacco RL, Diener HC, Weimar C (2008) Predicting long-term outcome after acute ischemic stroke: a simple index works in patients from controlled clinical trials. Stroke 39:1821-1826

3. Weimar C, Konig IR, Kraywinkel K, Ziegler A, Diener HC (2004) Age and National Institutes of Health Stroke Scale Score within 6 hours after onset are accurate predictors of outcome after cerebral ischemia: development and external validation of prognostic models. Stroke 35:158-162

4. Weimar C, Ziegler A, Konig IR, Diener HC (2002) Predicting functional outcome and survival after acute ischemic stroke. J Neurol 249:888-895

5. Chandratheva A, Geraghty OC, Rothwell PM (2011) Poor performance of current prognostic scores for early risk of recurrence after minor stroke. Stroke 42:632-637

6. Michel P, Odier C, Rutgers M, Reichhart M, Maeder P, Meuli R, Wintermark M, Maghraoui A, Faouzi M, Croquelois A, Ntaios G (2010) The Acute Stroke Registry and Analysis of Lausanne (ASTRAL): design and baseline analysis of an ischemic stroke registry including acute multimodal imaging. Stroke 41: 2491-2498

7. European Stroke Organisation (ESO) Executive Committee; ESO Writing Committee (2008) Guidelines for management of ischaemic stroke and transient ischaemic attack. Cerebrovasc Dis 25:457-507

8. Hacke W, Kaste M, Bluhmki E, Brozman M, Davalos A, Guidetti D, Larrue V, Lees KR, Medeghri Z, Machnig T, Schneider D, von Kummer R, Wahlgren N, Toni D (2008) Thrombolysis with alteplase 3 to 4.5 hours after acute ischemic stroke. N Engl J Med 359:1317-1329

9. Hacke W, Kaste M, Fieschi C, von Kummer R, Davalos A, Meier D, Larrue V, Bluhmki E, Davis S, Donnan G, Schneider D, DiezTejedor E, Trouillas P (1998) Randomised double-blind placebocontrolled trial of thrombolytic therapy with intravenous alteplase in acute ischaemic stroke (ECASS II). Second EuropeanAustralasian Acute Stroke Study Investigators. Lancet 352: $1245-1251$

10. Adams HP Jr, Bendixen BH, Kappelle LJ, Biller J, Love BB, Gordon DL, Marsh EE III (1993) Classification of subtype of acute ischemic stroke. Definitions for use in a multicenter clinical trial. TOAST. Trial of Org 10172 in Acute Stroke Treatment. Stroke 24:35-41

11. European Agency for the Evaluation of Medicinal Products (2002) Actilyse. Committee for Proprietary Medicinal Products (CPMP). http://www.ema.europa.eu/docs/en_GB/document_library/ Referrals_document/Actilyse_29/WC500010327.pdf. Accessed 21 Aug 2011

12. Food and Drug Administration (2002) Ativase (Alteplase, recombinant). http://www.fda.gov/downloads/Drugs/Development ApprovalProcess/HowDrugsareDevelopedandApproved/Approval Applications/TherapeuticBiologicApplications/ucm080871.pdf. Accessed 21 Aug 2011

13. Mishra NK, Lyden P, Grotta JC, Lees KR (2010) Thrombolysis is associated with consistent functional improvement across baseline stroke severity: a comparison of outcomes in patients from the Virtual International Stroke Trials Archive (VISTA). Stroke 41:2612-2617

14. Wahlgren N, Ahmed N, Eriksson N, Aichner F, Bluhmki E, Davalos A, Erila T, Ford GA, Grond M, Hacke W, Hennerici MG, Kaste M, Kohrmann M, Larrue V, Lees KR, Machnig T, Roine RO, Toni D, Vanhooren G (2008) Multivariable analysis of outcome predictors and adjustment of main outcome results to baseline data profile in randomized controlled trials: Safe Implementation of Thrombolysis in Stroke-Monitoring Study (SITS-MOST). Stroke 39:3316-3322

15. Bluhmki E, Chamorro A, Davalos A, Machnig T, Sauce C, Wahlgren N, Wardlaw J, Hacke W (2009) Stroke treatment with alteplase given $3.0-4.5 \mathrm{~h}$ after onset of acute ischaemic stroke 
(ECASS III): additional outcomes and subgroup analysis of a randomised controlled trial. Lancet Neurol 8:1095-1102

16. Hacke W, Donnan G, Fieschi C, Kaste M, von Kummer R, Broderick JP, Brott T, Frankel M, Grotta JC, Haley EC Jr, Kwiatkowski T, Levine SR, Lewandowski C, Lu M, Lyden P, Marler JR, Patel S, Tilley BC, Albers G, Bluhmki E, Wilhelm M, Hamilton S (2004) Association of outcome with early stroke treatment: pooled analysis of ATLANTIS, ECASS, and NINDS rt-PA stroke trials. Lancet 363:768-774

17. Ntaios G, Egli M, Faouzi M, Michel P (2010) J-shaped association between serum glucose and functional outcome in acute ischemic stroke. Stroke 41:2366-2370

18. Kruyt ND, Biessels GJ, Devries JH, Roos YB (2010) Hyperglycemia in acute ischemic stroke: pathophysiology and clinical management. Nat Rev Neurol 6:145-155

19. Parsons MW, Barber PA, Desmond PM, Baird TA, Darby DG, Byrnes G, Tress BM, Davis SM (2002) Acute hyperglycemia adversely affects stroke outcome: a magnetic resonance imaging and spectroscopy study. Ann Neurol 52:20-28

20. Ntaios G, Bath P, Michel P (2010) Blood pressure treatment in acute ischemic stroke: a review of studies and recommendations. Curr Opin Neurol 23:46-52

21. Adams HP Jr, del ZG, Alberts MJ, Bhatt DL, Brass L, Furlan A, Grubb RL, Higashida RT, Jauch EC, Kidwell C, Lyden PD, Morgenstern LB, Qureshi AI, Rosenwasser RH, Scott PA, Wijdicks EF (2007) Guidelines for the early management of adults with ischemic stroke: a guideline from the American Heart Association/American Stroke Association Stroke Council, Clinical Cardiology Council, Cardiovascular Radiology and Intervention Council, and the Atherosclerotic Peripheral Vascular Disease and Quality of Care Outcomes in Research Interdisciplinary Working Groups: the American Academy of Neurology affirms the value of this guideline as an educational tool for neurologists. Stroke 38:1655-1711 